\title{
DETECTIONS AND INTERPRETATION OF INFRASOUNDS SIGNALS RECORDED BY INFRAOUNDS STATIONS IN SOUTH AMERICA
}

Brandow Lee Neri (1), Lucas Vieira Barros (1), Juraci Mário de Carvalho (1)

(1) Seismological Observatory - University of Brasilia

\begin{abstract}
In this work we present some results of infrasound detections by stations in south America, especially detected by Brasília Station, identification code IS09BR. We analyzed infrasound signals generated naturally: by earthquake, vulcano eruption and bolide, and artificially, by chemistry explosion in queries located in Brasilia region. Before that we present some technical and Scientifics aspects of the Infrasound Technology, employed mostly to detect nuclear atmospheric explosions.
\end{abstract}

\section{Introduction}

In conjunction with the analysis of seismic, hydro-acoustic and radionuclide data, infrasound is one of the four technologies employed in the detection of clandestine nuclear explosions, i.e, explosions in violation of the Comprehensive Nuclear-Test-Ban Treaty (CTBT), particularly those made in atmospheric environment. However, other natural and artificial phenomena also produce infrasonic signals, such as chemical explosions, earthquakes, volcanic eruptions, bolide, etc.
The Brasilia Infrasound Station, 109BR, is part of the Comprehensive Nuclear Test Ban Treaty Organization (CTBTO) monitoring network - IMS (Figure 1), constantly records waves of natural and artificial infrasound. In the atmosphere, the propagation of infrasound waves is driven by wind currents and temperature (De Groot-Hedlin et al., 2010). They can reach global distances due to the low attenuation due to the long wavelengths of the infrasonic signals.

The Brasilia Station is an array of four symmetrically distributed sensors (microbarometers), each occupying the vertex of an equilateral triangle and one in the center. The data collected within the PNB are transmitted to the Seismological Observatory of the University of Brasília, where they are recorded, analyzed and retransmitted to the IDC (National Data Center), located in Vienna - Austria.

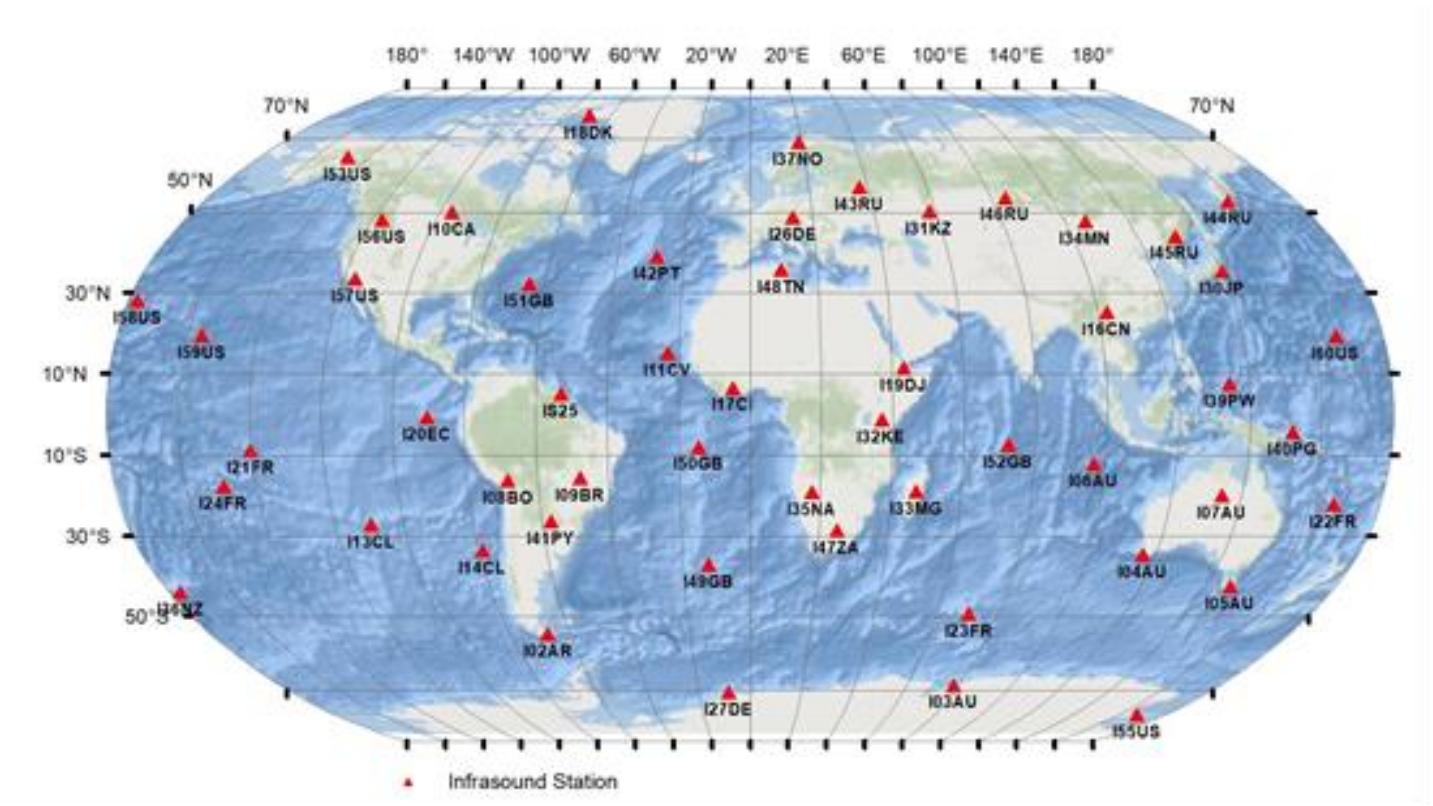

Figure 1 - Infrasound network of the International Monitoring System (IMS).

The implementation of a continuous monitoring of infrasound data with the I09BR Station will be of great importance for the advance of the detection and understanding of infrasound sources originating in Brazil, South America and the Caribbean. With the help of Latin American stations, you can identify and detail local and regional sources of information. 


\section{Method}

The infrasound data are processed using the Progressive Multichannel Correlation (PMCC) technique (Cansi, 1995; Cansi and Klinger, 1997). This technique was originally developed for application to seismic data. However, it was also efficient for the extraction of low amplitude signals and frequencies, contaminated by noise, as is the case with infrasonic signals.

Processing with the PMCC technique is performed consecutively in 11 frequency ranges, ranging from 0.07 to $4.0 \mathrm{~Hz}$, covering the entire spectrum of interest for the detection of infrasound signals. The duration of the processing window depends inversely on the frequency band. The first processing stage produces elemental detections, called PMCC pixels, which meet a correlation and consistency criteria. The next step is grouping individual detection pixels that have similar signal attributes: time, frequency, backazimuth, and horizontal speed. Groups of neighboring pixels constitute an "infrasonic family".

The categorization process examines the detections of the infrasound signals and classifies them in "phase" or "noise". Phases are detections that can later be associated with signals generated by events related to human activity or to natural phenomena. The notion of phase and noise applied to the infrasound data is directly related to I09BR station monitoring, which together with another 59 stations spread across five continents (Figure 1), make up the infrasound network of the International Monitoring System (IMS). The network is capable of detecting any nuclear explosion in any of the three environments: aquatic masses, atmosphere and underground, with yield equal to or greater than 1 kiloton of TNT (Trinitrotoluene).
The processing methodology used in this work is to detect the signals and extract their characteristics, such as back azimuth, horizontal velocity, frequency content, amplitude and duration of the signals detected by the infrasound station of Brasília - IS09 and the stations of Bolivia and Argentina.

\section{Results}

\section{Bolide}

On May 7, 2014, a luminous object coming from space was recorded by the cameras of the Brazilian Meteorite Monitoring Network, around 05:26 min (Figure 2). An event of this size generates infrasound waves with specific frequencies that were detected by the IS09 microbarographs (Figure 3).

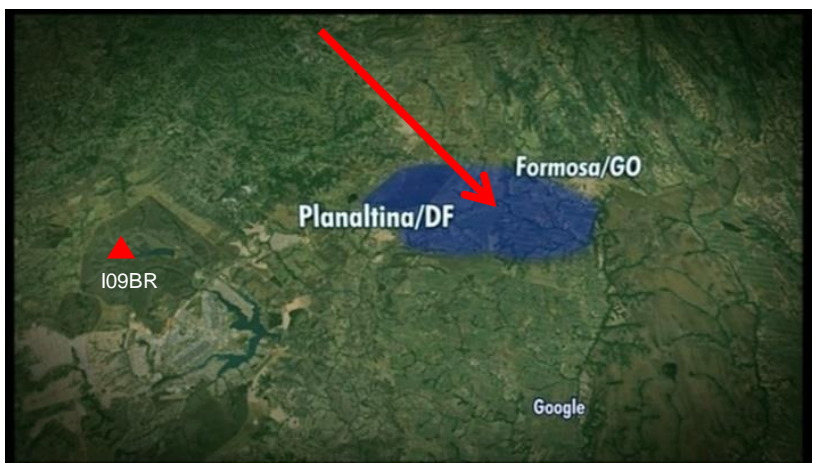

Figure 2 - Meteorite trail. Triangle denotes the station location and the blue area is the problable impact location on the ground.

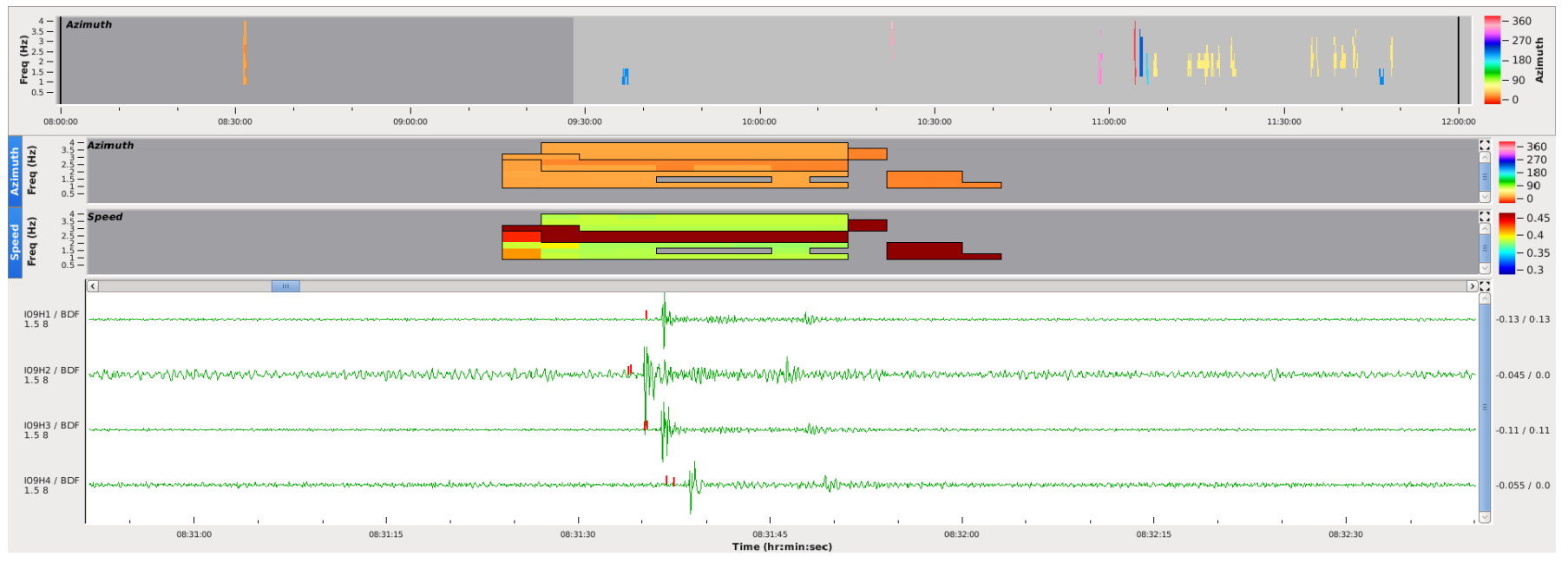

Figure 3 - Infrasound records of the four elements waveform (lower panel) of the meteorite detected by the I09BR station (below) and correspondent family detections (upper panel). 


\section{Volcano eruptions}

According to Chile's Volcanic Surveillance Network, the Calbuco volcano, located about 1,000 kilometers south of Santiago de Chile, erupted explosively on April 22, 2015. The activity intensified on the 23rd, lasting six hours. The explosions of the eruption generated infrasonic signals that were recorded by stations I09BR in Brazil, I08BO in Bolivia and I02AR in Argentina (figure 4).

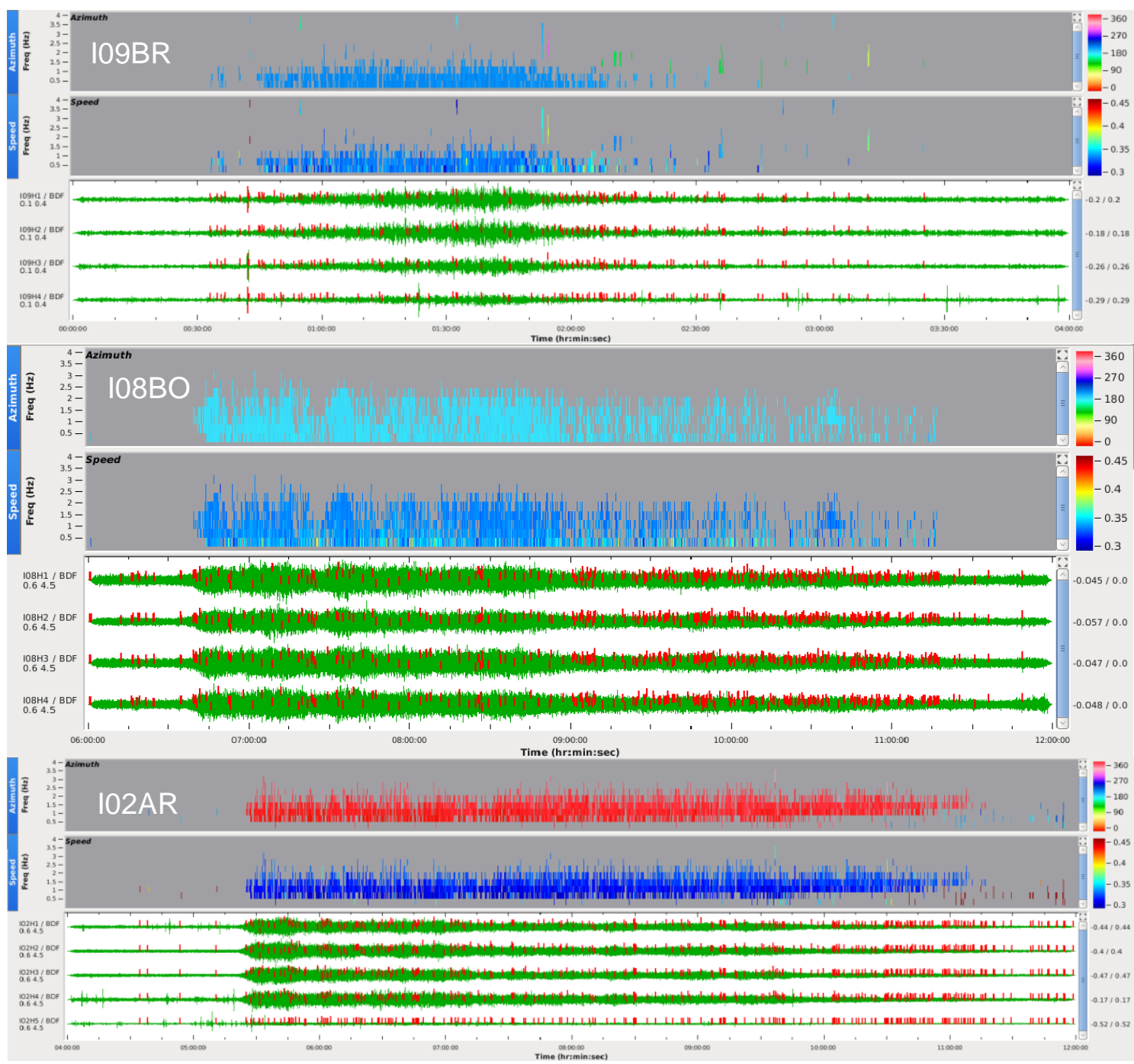

Figure 4 - Infrasound record of the eruption of the Calbuco volcano.

It can be observed that there is a long duration of the infrasonic family and the measured speed of propagation in each season is similar. Based on the calculated azimuths a preliminary location of the signal source was performed (Figure 5).

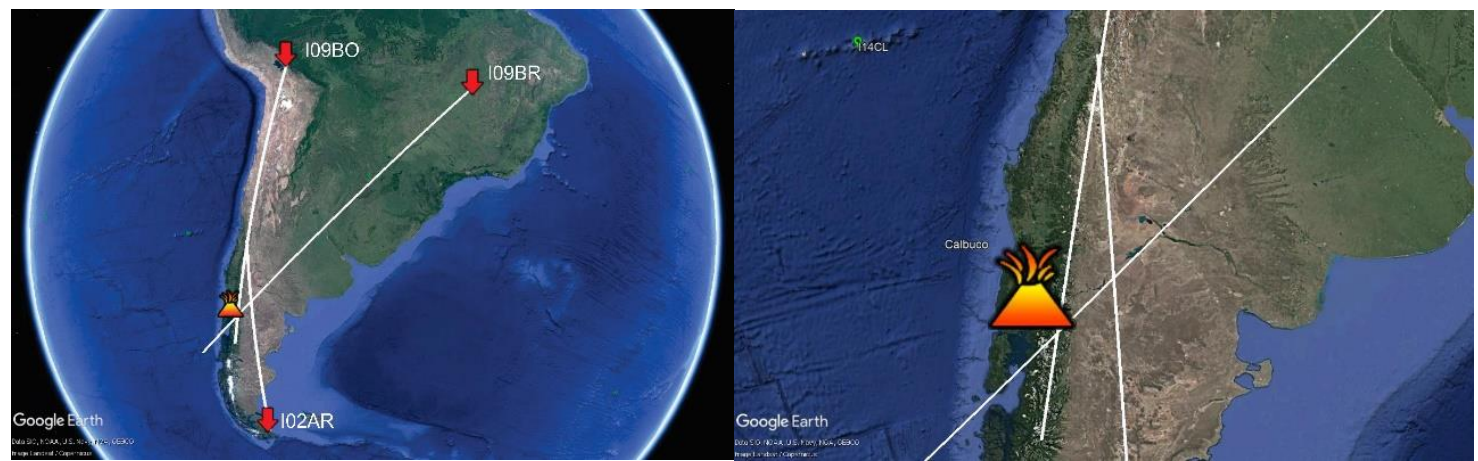

Figure 5 - Preliminary location of the Calbuco volcano eruption using the infrasound data analysis 


\section{Peru Earthquake}

An earthquake of magnitude 7.1 on the Richter scale, with an epicenter in Peru (Latitude: $11.12^{\circ} \mathrm{S}$, Longitude: $70.87^{\circ} \mathrm{W}$ and depth: $629 \mathrm{~km}$ ) and time of origin: 2018-08-24 09:04:07) generated an infrasound signal and was detected by the micro-barograph arrangements of Bolivia and Brazil. However, by the distance a the Brazilian station record was unable to calculate the pixel families using the technique of progressive channel correlations (Figure 6).

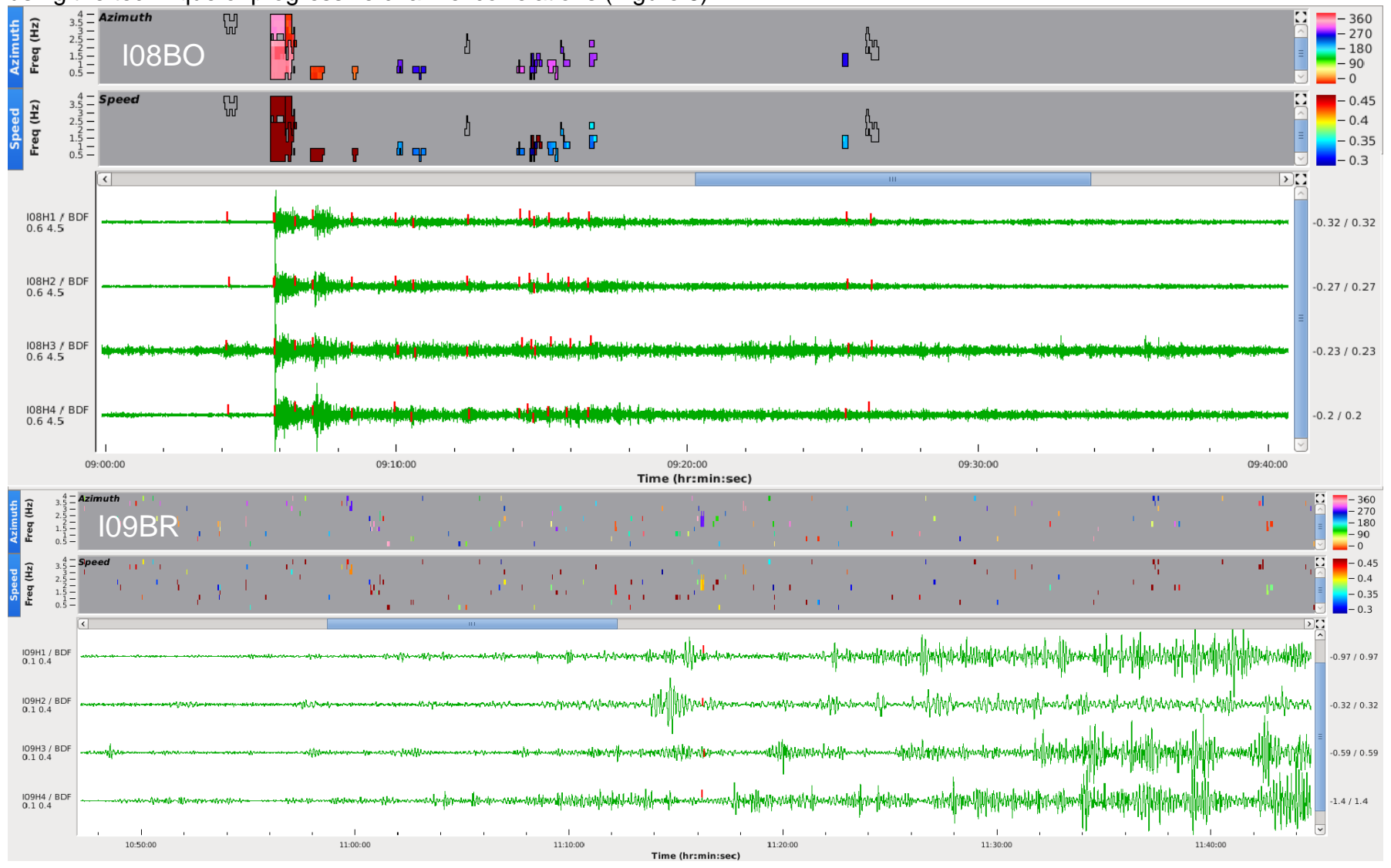

Figure 6 - Infrasound record of the Peru earthquake.

\section{Quarry Blast}

Mining plays a fundamental role in the Brazilian economy most of the country's mining companies are concentrated in Minas Gerais state. Exploration often occurs from dynamite detonations to rock fragmentation, and these explosions generate infrasonic sign Figure 7 shows a detection of a Quarry blast realized 200km away from the station IS09, in the Paracatu town. Figure 8 shows the correspondent location made with I09BR station.

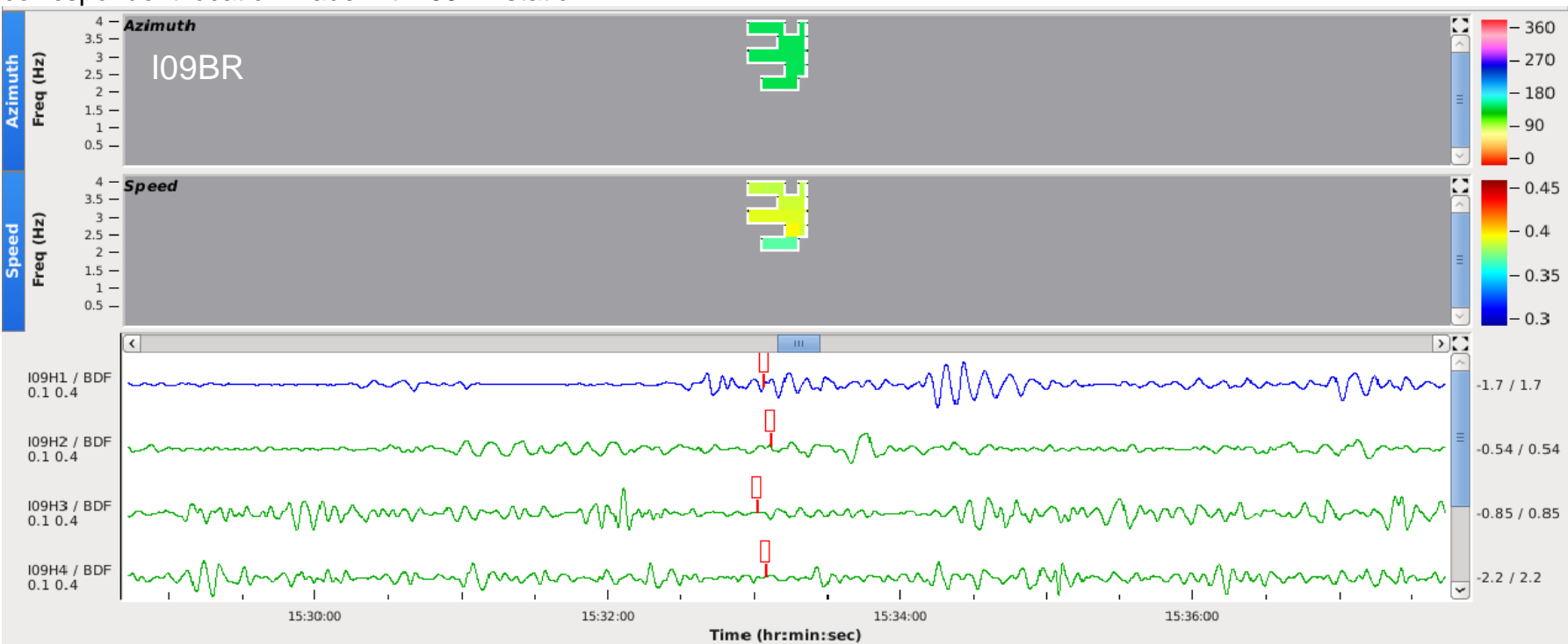

Figure 7- Records of infrasound quarry blast. Above panel are the detection families and below panel are the waveform from the four infrasound elements. The family color represents the backazimuth of the signal.

sixteenth International Congress of the Brazilian Geophysical 


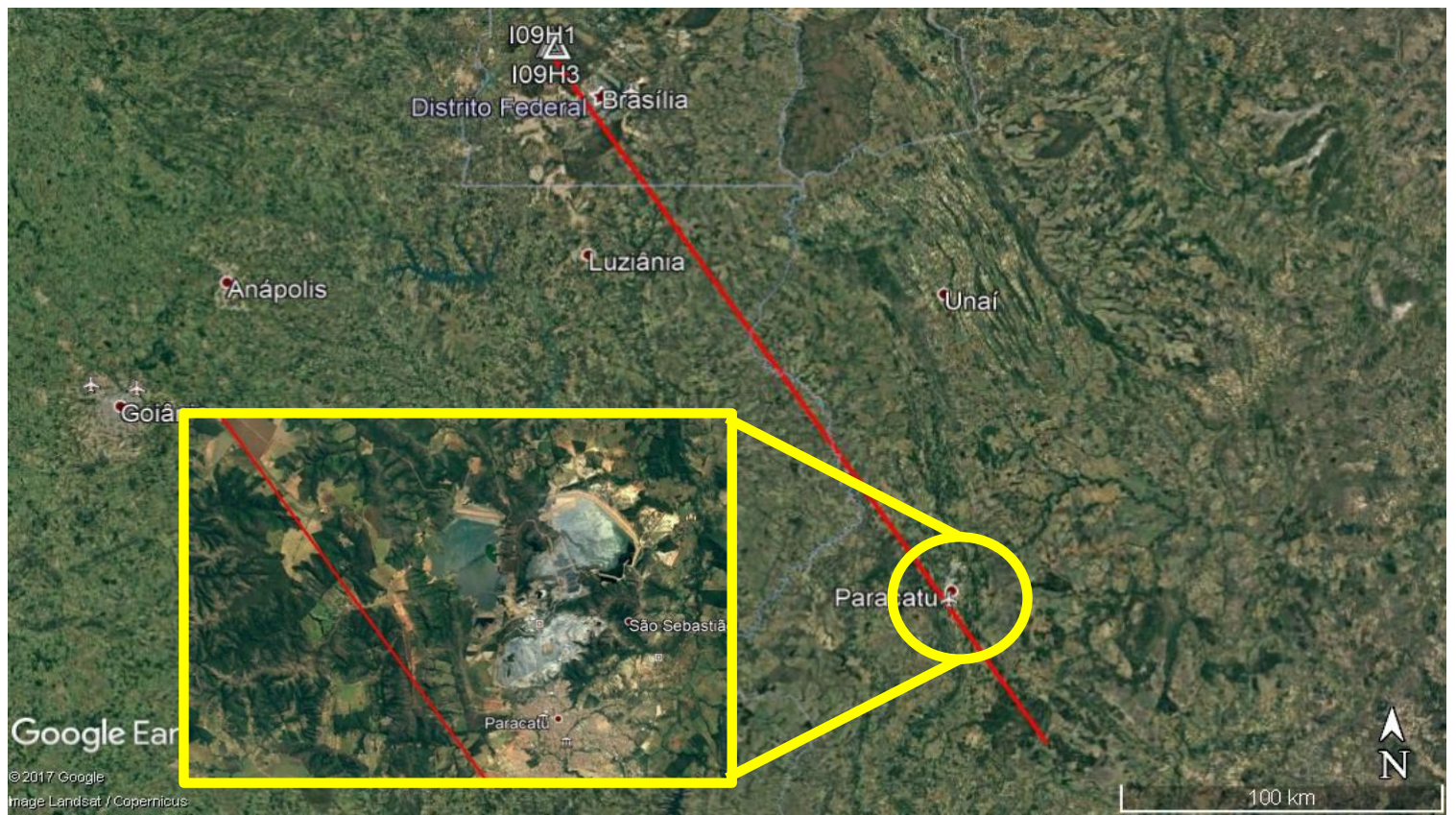

Figure 8-Preliminary location of the Paracatu quarry blast detected by IS09 station. Red line shows the azimuth of the location.

\section{Discussion and Conclusions}

Infrasound is a relatively new technology; therefore, the world's scientific community are still conducting researches in the field. The Comprehensive Nuclear Test Ban Treaty (CTBTO), a United Nations organization, promotes every two years a world congress to discourse and present new works on the subject (Science and Technology Conference - SnT). In addition to that, it annually promotes an infrasound workshop. Thus, Brazil, through UnB, integrates this select group of researchers aiming to monitor and comply with the Comprehensive Nuclear Test Ban Treaty - CTBT, especially in the field of infrasonic technology.

Continuous data monitoring is important for the understanding of sources with local, regional and global origin. This work aims to present the technology of the infrasound and its main detections.

The infrasound station installed in Brasilia showed to be efficient to detect and locate, in conjunction of other stations within South America, natural and manmade events. With the detection of infrasound waves from the Peru earthquake, showed the possibility to work in synergy with seismic technology.

\section{References}

Bass he (1972). atmospheric absorption of sound: analytical expressions. j acoustic soc am 52:821-825

Barros, L.V., Fontenele, D.P., (2002). IS09 Infrasound Station - International Monitoring System, Final Report - site preparation, construction and installation. 254pp.

Barros, L.V., (2000). Uma estação de infrassom em Brasília para verificar o comprimento do Tratado de Proibição Total de Testes Nucelares. Projeto de Pesquisa CNPq, 900.0018/90, 32 p.

Brachet $n$, Coyne J, Le Bras R (2006). Latest developments in the automatic and interactive processing of infrasound data at the IDC. infrasound technology workshop, Fairbanks, Alaska

Cansi Y (1995). An automatic seismic event processing for detection and location: the PMCC method. geophys res lett 22:10211024

Mcadie, AG, Taal, Asama-Yama and Katmai, (1912). Bull Seism Soc Am 2:233-242 mutschlecner jp, whitaker rw (2010) some atmospheric effects on infrasound signal amplitudes, this volume pp. 449-468

Salby $\mathrm{ml}$ (1996). Fundamentals of atmospheric physics. academic press, San Diego shaw wn, dines wh (1904) the study of the minor fluctuations of atmospheric pressure. q JR Meteorol soc 31:39-52. 